\section{Epigenetik beeinflusst Allergie und Toleranz}

\author{
Neben Erbgut und Umwelteinflüssen spielt eine dritte Kraft eine \\ Rolle bei der Entwicklung von Allergien: die Epigenetik.
}

Z u den epigenetische Vorgängen zählen Veränderungen der Genfunktion, die nicht auf Mutation beruhen. Dabei geht es um die Regulation der Transkription und demzufolge um die Verfügbarkeit und den Gebrauch genetischer Information. Drei Mechanismen stehen im Vordergrund: die Modifikation von Histonen, die posttransskriptionale Modifikation durch Mikro-RNA (miRNA) oder "small interfering RNA“ (siRNA) und die DNA-Methylierung.

Mit den Einflüssen der Epigenetik auf Allergieentstehung und Toleranzentwicklung hat sich Michael Kabesch befasst. Er betont die zentrale Position epigenetischer Prozesse in der Immunregulation, weil sie eine rasche Anpassung an Gefahrensignale und ein Ab- und Anschalten von Reaktionswegen in einer zellspezifischen Weise erlauben. Epigenetische Signaturen sind laut Kabesch an allen Aspekten des Allergiegeschehens beteiligt. Mit ihnen lassen sich Individuen identifizieren, die anfällig sind für Allergien, noch bevor diese symptomatisch wird; die Signaturen sind mit allergischen Erkrankungen assoziiert, und sie stehen auch in Zusammenhang mit der erfolgreichen Induktion von Toleranz.

Bestimmte DNA-Methylierungsmuster sind z. B. typisch für Gene, die für IL-4und IL-5-Rezeptoren kodieren und die schon früher mit Allergien und IgESpiegeln in Verbindung gebracht wurden. Über die Methylierung lässt sich ein viel größerer Anteil der IgE-Varianz in der Bevölkerung erklären als mit den Einzelnukleotid-Polymorphismen, die mit IgE zusammenhängen. Unterschiede im Methylierungsmuster sind etwa bei Patienten mit atopischer Dermatitis und Patienten mit Asthma gefunden worden.

Allergologisch interessant an den epigenetischen Vorgängen ist ihre prinzipielle Reversibilität. Kabesch hält es für möglich, dass diese Eigenschaft als Schlüssel für die Induktion von Toleranz, damit für die Umkehrung der allergischen Reaktion und eine echte Heilung von Allergien dienen könnte. Dass epigenetische Mechanismen manipulierbar sind, zeigen beispielsweise Studien zur Immuntherapie von Erdnussallergie.

Fazit: Diese Erkentnisse lassen auf neue Therapien hoffen. Manche epigenetischen Modifikatoren sind ohnehin schon längst im Einsatz: Glukokortikoide. Allerdings setzen sie ungezielt an. Entwickelt werden sollen Möglichkeiten zur zielgenauen Manipulation, so wie die Natur sie vormacht: zellspezifisch.

Dr. Robert Bublak

Kabesch M et al. Epigenetic determinants of allergy and tolerance. Allergo J Int 2016; 25: 154-9

\section{Was kann die Immuntherapie auf Peptidbasis?}

\section{Durch die Verwendung von synthetischen Peptiden anstelle von intakten Proteinallergenen sollen Dauer und Nebenwirkungsrisiko der SIT reduziert werden. Erste Phase-Illb-Studien sind Erfolg versprechend.}

D ie klassische Immuntherapie stellt erhebliche Anforderungen an die Compliance: drei Jahre lang monatliche Injektionen oder tägliche sublinguale Einnahme in Verbindung mit einer relativ hohen Rate an Nebenwirkungen. Diese Hürden hofft man zu umgehen, indem man die allergenen Proteine durch kurze synthetische Peptide ersetzt, die die immundominanten T-Zell-Epitope repräsentieren. Den Stand der Forschung zur peptidbasierten Immuntherapie bei IgE-vermittelten allergischen Erkrankungen haben Elena Tonti und Mark Larché zusammengefasst.

Üblicherweise wird eine Mischung aus Peptiden verwendet, die nur 13 bis 17 Aminosäuren lang sind und mit mittlerer bis hoher Affinität an MHC-Klasse-II-Moleküle binden. Sie sind zu kurz, um ein Crosslinking von IgE-Antikörpern zu verursachen, aber in der Lage, die T-Zell-Antwort zu modulieren. Geeignete Epitope werden im Computer und mit In-vitro-MHC-Bindungsassays identifiziert und ex vivo mit T-Zell-Aktivierungs-Tests validiert. Die Applikation erfolgt bevorzugt intradermal; die Antigen-präsentierenden Zellen in der Dermis sorgen für eine effiziente und tolerogene Präsentation der Peptide. Der Wirkmechanismus der Peptide ist noch nicht ganz geklärt. Im Gegensatz zu intakten Allergenen scheint die Behandlung weder eine Deletion allergenspezifischer T-Zellen noch eine Induktion blockierender IgG-Antikörper zu bewirken. Stattdessen wird offenbar die allergenspezifische T-Zell-Antwort verändert und eine CD4+-Zellpopulation mit Suppressor-Eigenschaften induziert. Die Produktion von Th2-Zytokinen nimmt ab und die von IL-10 geht nach oben. Außerdem kann sich die Toleranz auch auf nicht therapierte Major-Allergene erstrecken.

$\mathrm{Zu}$ den größten Vorteilen der Peptide im Vergleich zu vollständigen Allergenen gehört die geringere Nebenwirkungsrate; sie erlaubt eine kürzere Therapiedauer, weil größere Mengen der Peptide auf einmal gegeben werden können. Bereits vier Injektionen über drei Monate haben sich als ausreichend erwiesen, um die Symptome einer allergischen Rhinokonjunktivitis anhaltend zu reduzieren.

Fazit: Entsprechende Resultate aus klinischen Phase-IIb-Studien liegen bislang für peptidbasierte Immuntherapien gegen Katzen-, Hausstaubmilben-, Gräserund Ambrosia-Allergien vor. Die Wirksamkeit der Präparate im Placebovergleich wurde in Expositionskammern bestätigt. Sicherheit und Verträglichkeit waren gut, Nebenwirkungen nicht häufiger oder schwerer als unter einer Scheintherapie.

Dr. Beate Schumacher

Tonti E et al. Concepts and perspectives on peptide-based immunotherapy in allergy. Allergo J Int 2016; 25: 144-53 